\title{
Asbestos fibres in bronchoalveolar lavage fluid from asbestos workers: examination by electron microscopy
}

\author{
A R GELLERT, ${ }^{1}$ J Y KITAJEWSKA,${ }^{2}$ S UTHAYAKUMAR, ${ }^{1}$ J B KIRKHAM, ${ }^{2}$ AND \\ R M RUDD ${ }^{1}$
}

From the Department of Thoracic Medicine, ${ }^{1}$ London Chest Hospital, London E2 9JX and Biological Electron Microscopy Unit, ${ }^{2}$ School of Biology, Queen Mary College, London E1 4NS, UK

ABSTRACT The uncoated and coated fibre load in bronchoalveolar lavage (BAL) fluid was assessed using light microscopy, scanning electron microscopy, and $x$ ray microanalysis in 15 subjects with previous, unprotected exposure to asbestos, including three with clinical and radiological evidence of asbestosis, and in 13 urban dwelling control subjects with no known occupational exposure to asbestos. The mean ferruginous body count per $\mathrm{ml} \mathrm{BAL}$ fluid in asbestos exposed subjects as determined by light microscopy was 52 (range 0-333). No ferruginous bodies were detected in control subjects. The mean fibre count per $\mathrm{ml}$ BAL fluid in asbestos exposed subjects as determined $\stackrel{\rho}{\supset}$ by electron microscopy was $793(133-3700)$, significantly greater than 239 (44-544) in controls (p $<\vec{\bullet}$ $0 \cdot 05)$. Electron microscopic counts correlated with duration of previous exposure to asbestos $(r=\infty$ $0.47, \mathrm{p}<0.05)$ and with percentage neutrophil counts $(\mathrm{r}=0.53, \mathrm{p}<0.025)$. There was no relation between electron microscopic fibre counts and light microscopic ferruginous body counts. In 11 asbestos exposed cases $x$ ray microanalysis confirmed the presence of asbestos and in six the asbestos fibre type was clearly identified. Of five subjects showing no asbestos bodies by light microscopy, all showed fibres by electron microscopy, and in three cases the presence of asbestos was confirmed by microanalysis. Among control subjects, fibres were either large organic fibres or smaller particles which microanalysis showed were not asbestos. In only one control case were a few fibres identified which were confirmed as asbestos fibres on microanalysis. Electron microscopic examination of BAL fluid may confirm past exposure to asbestos and probably gives a crude quantitative estimate of asbestos load.

In the past 15 years recovery and analysis of asbestos fibres and bodies from human lung tissue have been the object of considerable study in the verification of previous exposure to asbestos. Evidence is accumulating to suggest that occupational exposure is associated with many more bodies per gram of lung tissue than non-occupational, or urban, exposure. ${ }^{1}$ The incidence and severity of lung fibrosis due to asbestos inhalation (asbestosis) increases as exposure dose is augmented $^{2}$ and the asbestos fibre load has been shown to be related to the severity of the disease in mild and moderate asbestosis. ${ }^{3}$ Indeed, we have encountered greater numbers of asbestos bodies per $\mathrm{ml}$ of bronchoalveolar lavage (BAL) fluid in patients with asbestosis ${ }^{45}$ than in asbestos workers without clinical or radiological evidence of asbestosis. ${ }^{67}$

Accepted 5 August 1985
In 1973 Ashcroft and Heppleston used light and $\frac{3}{3}$ electron microscopy to examine human asbestotic lung and showed that uncoated fibres outnumbered $\frac{\mathrm{O}}{3}$ coated fibres. $^{3}$ They suggested that there was an approximate relation between the number of optically visible fibres and the total asbestos concentration as? judged by electron microscopy. On the other hand, Churg and Warnock showed that many asbestos N fibres detected in the lungs of urban dwellers by electron microscopy were too small to form asbestos bod-D ies or to be visible by light microscopy. ${ }^{8}$ They sug- $\omega$ gested that asbestos bodies may serve as some indication of exposure to long amphiboles but not aso an index of total asbestos fibre load.

Several studies examined the fibre load of histolog $\stackrel{?}{-}$ ical tissue using electron microscopy have been published. ${ }^{138-14}$ Recently, both coated and uncoated asbestos fibres have been detected in the sputum of 
asbestos workers using transmission and scanning electron microscopy as long as 15 years after exposure to asbestos had ceased. ${ }^{15}$

BAL is a relatively non-invasive means of sampling cellular and other material from the peripheral air spaces of the lung. The technique may therefore be potentially useful in the study of previous asbestos exposure, particularly among those asbestos workers, including some with established asbestosis, who do not produce sputum. There is often doubt regarding the nature and extent of past exposure to asbestos, particularly in cases of possible industrial compensation for asbestos related pulmonary disease including lung cancer; such information can be provided by mineralogical analysis of lung tissue but this may be performed only after open lung biopsy or after death. BAL permits assessment during life. De Vuyst and colleagues reported the mineralogical analysis of BAL fluid using electron miscroscopy in the case of a 57 year old Turkish woman with pleural disease but the authors did not provide quantitative details of the fibre load. ${ }^{16}$ Bignon and colleagues used light microscopy and transmission electron microscopy to study mineral particles in BAL fluid from a variety of patients including some with asbestos related diseases. ${ }^{17}$ Apart from these studies, there has been little published work on the electron microscopic examination of BAL fluid from asbestos workers.

The purposes of the present study were to use electron microscopy to examine the uncoated fibre load in BAL fluid from asbestos workers with known previous occupational exposure to asbestos in order to examine relations between electron microscopic fibre counts, light microscopic ferruginous body counts, and the clinical history of exposure to asbestos and to compare BAL fibre loads from asbestos workers with urban dwelling controls.

\section{Methods}

\section{PATIENTS}

The study group consisted of 14 men and one woman (mean age 49, range 36-68) with previous heavy, unprotected occupational exposure to asbestos. Three had clinical and radiological evidence of asbestosis and eight had radiological evidence of pleural disease. The mean time since first exposure to asbestos was 30 years (range 16-46) and the mean duration of exposure was 16 years (range 1-30). The mean time since last exposure to asbestos was eight years (range $0-18$ ). Thirteen subjects has worked in the lagging industry, one had carried out asbestos cutting and milling, and one had suffered exposure predominantly from dust on the clothing of relatives working in the asbestos industry. The three patients with asbestosis were current smokers. The asbestos exposed subjects without asbestosis had ceased smoking at least five years previously or had never smoked.

\section{CONTROL SUBJECTS}

Ten men and three women (mean age 58, range 26-73) who had no history of occupational exposure to asbestos, either personally or through a relative in the same household, and who were undergoing fibreoptic bronchoscopy for the investigation of respiratory symptoms acted as controls for BAL fluid electron microscopic fibre counts. All 13 subjects resided in urban areas similar to the study population. Seven were tobacco smokers.

\section{BRONCHOALVEOLAR LAVAGE}

BAL was performed after premedication with atropine, under local anaesthesia with lignocaine, through an Olympus fibreoptic bronchoscope (type BF3). Patients with impaired lung function received supplemental oxygen through a nasal speculum. BAL was performed after the tip of the bronchoscope was gently wedged into a basal segment of either lower lobe; $3 \times 50 \mathrm{ml}$ aliquots of sterile physiological saline warmed to body temperature were introduced and then aspirated. Aspirated fluid was collected into a sterile sili-conised glass container and transported immediately to the laboratory for examination.

All patients gave informed consent for the procedure and approval from the local ethical committee was obtained.

\section{EXAMINATION BY LIGHT MICROSCOPY}

All technical procedures were performed without delay using siliconised glass or plastic materials to minimise loss of cells by adherence. After the total volume of fluid was measured, $20 \mathrm{ml}$ were centrifuged at $300 \mathrm{~g}$ for 10 minutes and the resulting pellet of cells was resuspended in $1 \mathrm{ml}$ of physiological saline. The total cell count was made in an improved Neubauer counting chamber (Gelman Hawksley Ltd, Lancing, England). Morphological examination was performed from slide preparations made using $100 \mu \mathrm{l}$ aliquots of cells suspension diluted to a concentration of $1.25 \times 10^{6} \mathrm{cells} / \mathrm{ml}$ and spun at $300 \mathrm{~g}$ for 10 minutes in a Shandon Cytospin centrifuge (Shandon Southern Products, Runcorn, Cheshire, England). The slides were air dried, fixed in methanol, and stained with May-Grunwald and Giemsa stains. Differential cell counts were made from a total of 300 cells. Macrophages, lymphocytes, neutrophils, and eosinophils were counted.

Manual counts of regular shaped and regular segmented ferroprotein coated fibres were carried out on samples prepared as follows: a $20 \mathrm{ml}$ aliquot of BAL fluid was centrifuged at $300 \mathrm{~g}$ for 10 minutes, the deposit was diluted with $0.5 \mathrm{ml}$ of $0.1 \mathrm{M}$ sodium 
hydroxide and spun at $300 \mathrm{~g}$ for 10 minutes in a Shandon Cytospin centrifuge to make slides that were air dried and fixed in methanol. Counts per slide were standardised to $1 \mathrm{ml}$ of fluid.

\section{ELECTRON MICROSCOPY}

Five millilitres of $10 \%$ formol saline were added to 5 $\mathrm{ml}$ of unadulterated BAL fluid and the sample was kept refrigerated at $4^{\circ} \mathrm{C}$ until processing for electron microscopic examination; this was carried out within two weeks of collection of the specimen.

The BAL specimen was mixed with $5 \mathrm{ml} 5 \%$ sodium hypochlorite solution and stirred at $70^{\circ} \mathrm{C}$ for one hour. Five millilitres of ether were added and the sample mixed in an ultrasonic bath for three minutes before passage through a $0.4 \mu \mathrm{m}$ nucleopore filter that was sputter coated (gold and palladium coated) and examined using a JEOL scanning electron microscope (model JSM-35, Japan) by an electron microscopist unacquainted with the clinical details.

The nucleopore filter was viewed at $\times 1000$ magnification and 50 fields were examined. Fifty fields of view represent $1.8 \%$ of the total area so that an estimate of the total number of fibres on the filter, and therefore the lavage sample, is given by the number of fibres in 50 fields of view $\times 100 / 1 \cdot 8$. Only particles with an aspect ratio of $3: 1$, recognised by investigators as fibrous, ${ }^{11}$ were counted.

The electron microscope was fitted with a Link energy dispersive $x$ ray microanalyser (model 290; Link Systems, High Wycombe, Bucks, England) allowing chemical microanalysis of uncoated fibres and the central core of ferruginous bodies. Appraisal of the proportion of constituent elements enabled the identification of fibre type ${ }^{18}$ The most suspicious looking fibres were analysed.

\section{STATISTICAL ANALYSIS}

The Mann-Whitney U test was used for group comparisons of quantitative data. Correlations were assessed using the Spearman rank correlation coefficient. Non-parametric statistics were used as the data were not normally distributed.

\section{Results}

BAL CELL COUNTS IN ASBESTOS WORKERS The mean total cell count per $\mathrm{ml}$ of BAL fluid was 889 $\times 10^{3}$ (range $360-1450 \times 10^{3}$ ). The differential cell counts showed mean percentages of 80 (49-96) for macrophages, 12 (1-42) for lymphocytes, six (2-15) for neutrophils, and less than one $(0-6)$ for eosinophils.

BAL ASBESTOS BODY AND FIBRE COUNTS IN ASBESTOS WORKERS AND CONTROL SUBJECTS The mean fibre count per ml BAL fluid in asbestos exposed subjects as determined by electron micros- $\frac{2}{3}$ copy was 793 (133-3700), significantly greater than $\stackrel{0}{\circ}$ 239 (44-544) in non-exposed controls (p < 0.05) (fig 1). The mean ferruginous body count per ml BAL fluid in asbestos exposed subjects as determined by light micoscopy was 52 (range 0-333). No ferruginous bodies were detected in control subjects. There was no $\frac{\overline{\bar{p}}}{\vec{D}}$ relation between fibre counts determined by electron $\mathbb{\nabla}$ microscopy and ferruginous body counts determined by light microscopy in asbestos exposed subjects. Tables 1 and 2 show BAL ferruginous body and fibre $\vec{\circ}$ counts for each subject and the results of $x$ ray micro- $\overrightarrow{\vec{A}}$ analysis of BAL fibres and ferruginous bodies. In $11 \mathrm{\omega}$ asbestos exposed cases microanalysis confirmed the $\bigcirc$ presence of asbestos and in six cases the asbestos fibre $\frac{\mathbb{T}}{3}$ type was clearly identified. Five subjects showing no asbestos bodies by light microscopy showed fibres by $\omega$ electron microscopy, and in three the presence of $\overrightarrow{ }$ asbestos was confirmed by microanalysis. In control $\stackrel{\partial}{ }$ subjects particles proved to be either large organic 옥 fibres or smaller fibres which microanalysis showed were not asbestos. In only one case were a few fibres $\bar{z}$ identified which were morphologically consistent with $\frac{0}{3}$ asbestos and which were confirmed to be asbestos $\supset$ fibres on microanalysis.

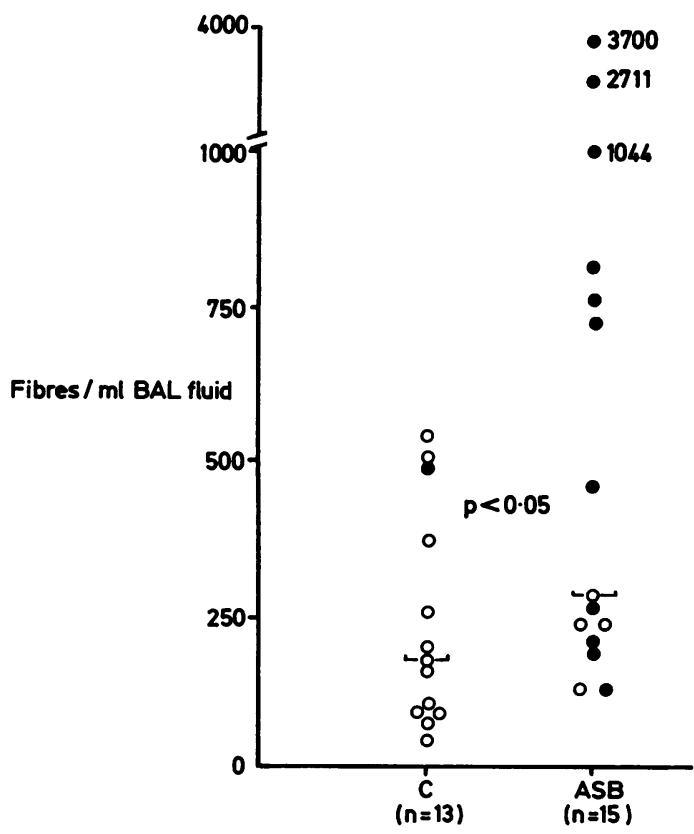

Fig 1 Fibre counts in BAL fluid as determined by electron microscopy in 15 asbestos exposed (ASB) and 13 control (C) subjects. Closed circles indicate cases in which asbestos was positively identified on $x$ ray microanalysis and open circles indicate cases in which asbestos was not identified on $x$ ray microanalysis. Horizontal bars indicate median values. 
Table 1 Fibre (electronmicroscopy) and ferruginous bodies (light microscopy) in BAL fluid from 15 asbestos workers

\begin{tabular}{lccll}
\hline Age & Duration of exposure (years) & Ferruginous bodies fibres & Microanalysis \\
\cline { 3 - 4 } & & (Light microscopy) & $(E / M)$ & \\
\hline $41^{*}$ & 13 & 0 & 133 & Large organic fibres: glass fibre \\
$38+$ & 4 & 0 & 133 & Asbestos \\
39 & 26 & 5 & 188 & Asbestos \\
$50+$ & 3 & 140 & 211 & Variety including amosite \\
43 & 5 & 1 & 233 & Probably asbestos \\
$68+$ & 20 & 0 & 233 & Fibres not suggestive of asbestos; \\
43 & 20 & 333 & 266 & non-fibrous silica dust present \\
$64+\mathrm{f}$ & 10 & 1 & 288 & Asbestos \\
$53+$ & 24 & 7 & 466 & Probably asbestos \\
36 & 20 & 0 & 722 & Arocidolite/amosite \\
$57+$ & 11 & 150 & 756 & Crostos and glass fibre \\
$58^{*}+$ & 15 & 15 & 811 & Asbestos and glass fibre \\
$60^{*}+$ & 27 & 1 & 1044 & Amosite/crocidolite and glass fibre \\
42 & 27 & 0 & 2711 & Amosite/chrysotile \\
46 & 30 & 130 & 3700 & Amosite \\
\hline
\end{tabular}

Numbers of fibres and bodies $=$ per $\mathrm{ml} \mathrm{BAL}$ fluid.

Asbestos = Fibres morphologically consistent with asbestos and microananlysis confirmed the presence of silica, but the proportions of elements present not typical of any particular fibre subtype.

Probably asbestos = Fibres appeared consistent with asbestos morphologically but microanalysis inconclusive.

* = Asbestosis.

$+=$ Pleural disease.

$f=$ Female.

Table 2 Fibre counts in BAL fluid from 13 control subjects

\begin{tabular}{lllll}
\hline Diagnosis & Age & Ferruginous bodies fibres & & Microanalysis \\
\cline { 2 - 4 } & & (Light microscopy) & $(E / M)$ & \\
\hline Pneumonia & 70 & 0 & 44 & Non-asbestos fibres \\
CFA & 73 & 0 & 78 & Non-asbestos fibres \\
Autoimmune vasculitis/FA & 66 & 0 & 89 & Non-asbestos fibres \\
Haemoptysis & 50 & 0 & 100 & Non-asbestos and some glass fibre \\
Tuberculosis & 48 & 0 & 167 & Non-asbestos fibres \\
Haemoptysis & 63 & 0 & 178 & Non-asbestos fibres \\
CFA & 68 & 0 & 189 & Non-asbestos fibres \\
Polymyositis/FA & 26 & 0 & 256 & Non-asbestos fibres; large organic fibres \\
Pulmonary mass & 59 & 0 & 378 & Non-asbestos fibres \\
CFA & 52 & 0 & 489 & Glass fibre; a few asbestos fibres of \\
Pneumonia & 69 & 0 & 511 & undetermined type \\
Sarcoidosis & 44 & 0 & 544 & Lon-asbestos fibres \\
CFA & 72 & 0 & & norge organic fibres and smaller \\
& & & &
\end{tabular}

Numbers of fibres $=$ per $\mathrm{ml}$ BAL fluid.

CFA = Cryptogenic fibrosing alveolitis.

FA = Fibrosing alveolitis.

Non-asbestos fibres = Microanalysis of particles with an aspect ratio of 3:1 or more did not show the elemental composition of asbestos.

Figures 2(a-c) show asbestos fibres and ferruginous bodies from BAL specimens as seen with the scanning electron microscope and fig 2(d) is the microanalysis pattern of a fibre from BAL fluid showing the elemental composition of amosite.

RELATIONS BETWEEN BAL FIBRE COUNTS, CLINICAL AND BAL VARIABLES IN ASBESTOS WORKERS

Electron microscopic fibre counts correlated with duration of exposure to asbestos $(r=0.47, p<0.05)$ and higher counts tended to be associated with longer time since first exposure to asbestos $(r=0.42, p<$ $0 \cdot 1)$. There was, however, no relation between fibre count and time elapsed since last exposure to asbestos. Electron microscopic fibre counts correlated with percentage neutrophil counts $(r=0.53, p<0.025)$ but there were no other relations between fibre counts and either BAL total or differential cell counts.

\section{Discussion}

This work has shown that the number of fibres identified by electron microscopy in BAL fluid from 


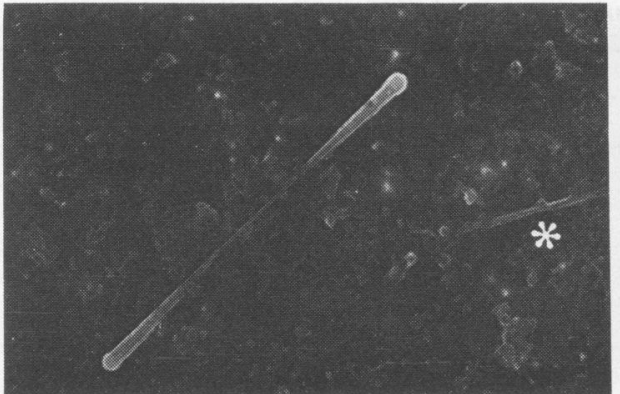

(a)

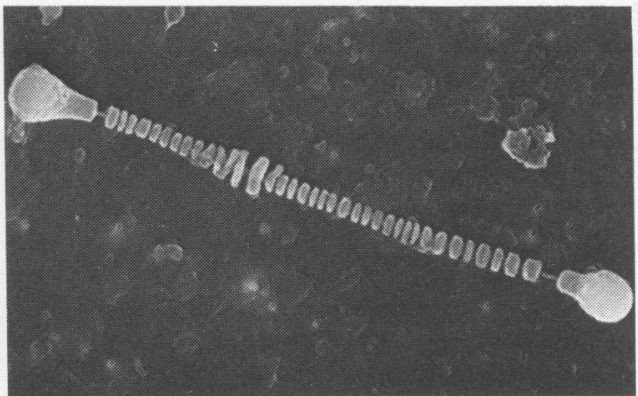

(b)

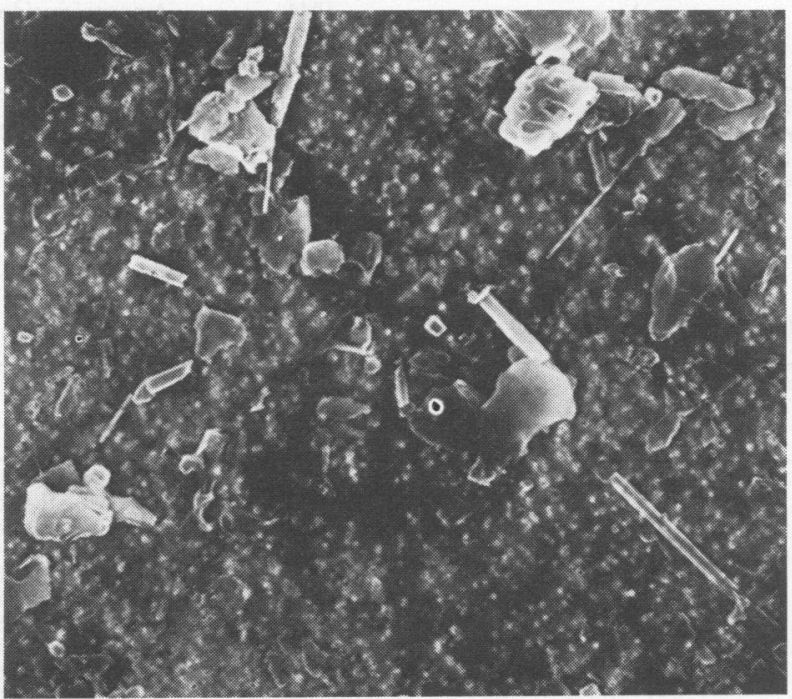

(c)

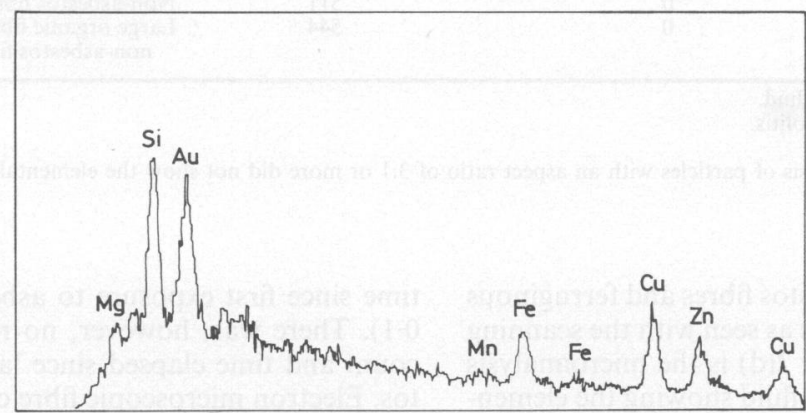

(d)

Fig 2 Typical ferruginous bodies found in bronchoalveolar lavage samples. Both fibres show polar development of ferruginous coat. In (a) coat is developing from poles of fibre towards its centre (magnification $\times 1200$ ). In contrast in $(b)$ coat has developed at specific sites and at regular intervals along fibre length (magnification $\times 1800$ ). Asterisk shows site of an uncoated fibre in $(a)(c)$ and $(d)$. Typical mixed population of fibres found in BAL samples (magnification $\times 1200$ ). Morphology of these fibres suggests that asbestos is amosite. This is confirmed by x ray microanalysis illustrated in (d). Amosite is represented by $\mathrm{Si}, \mathrm{Mg}, \mathrm{Mn}$, and $\mathrm{Fe}$ peaks. $\mathrm{Au}, \mathrm{Cu}$, and $\mathrm{Zn}$ peaks are products of technique. 
asbestos workers is much greater than the number of asbestos bodies determined by light microscopy in the same specimens. Moreover, fibres were detected in five cases in whom light microscopy had failed to show ferruginous bodies, and in three of these microanalysis confirmed the presence of asbestos. Uncoated fibres may be identified using light microscopy but identification is difficult and requires considerable expertise with the use of phase contrast techniques. It is of interest that fibre counts correlated with BAL neutrophil percentages. Increases in BAL neutrophils are a common feature in asbestosis ${ }^{45}$ and sometimes occur in asbestos exposed subjects with no clinical or radiological evidence of asbestosis. ${ }^{67}$ Future observation will show whether the presence of higher fibre and neutrophil counts are predictive of the development of asbestosis.

The quantitative value, however, of BAL fibre counts should not be overestimated. The fibre count, even in occupationally exposed subjects, encompassed both asbestos and other, usually organic, fibres. Although many fields are examined with the scanning electron microscope, they represent only $1.8 \%$ of the total area so errors in field counts may yield errors in the final estimate. The positive identification of asbestos on microanalysis is probably of greater significance than the overall fibre count; this is underlined by the fact that asbestos fibres were identified in only one control case, despite some overlap numerically in fibre counts between the study and the control populations.

Among the 11 workers exposed to asbestos in whom asbestos of some sort was detected, chrysotile was definitely identified in only one instance, whereas amosite or crocidolite were detected in six and asbestos of uncertain classification in five. It is not surprising that little chrysotile was identified. Ashcroft and Heppleston found relatively little chrysotile on electron microscopic examination of asbestotic lungs ${ }^{3}$; the authors commented that it was most unlikely that chrysotile was lost during centrifugation in preparation of specimens for the grids since control specimens made without centrifugation showed a similar predominance of amphibole fibres. It is thought that chrysotile is cleared from the lungs more rapidly than amphiboles, either because it tends to split into fibrils or because its magnesium leaches out causing it to break up and dissolve. ${ }^{2}$ Gylseth studied Norwegian asbestos cement workers exposed predominantly to chrysotile asbestos and showed that the percentage of chrysotile asbestos in lung tissue varied between $0 \%$ and $9 \%$ whereas corresponding figures for the amphiboles were $76 \%$ to $99 \% .{ }^{12}$ Similarly, Pooley ${ }^{19}$ and Churg and Warnock ${ }^{9}$ showed that asbestos bodies rarely contain a chrysotile core. In our study microanalysis of BAL fluid from one patient with asbestosis showed only glass fibre and in another asbestos worker asbestos was not detected on microanalysis. The times since last exposure to asbestos in these cases were respectively 17 and seven years and in neither case were asbestos bodies found on light microscopy, suggesting the possibility that exposure had been predominantly to chrysotile which had been subsequently cleared from the lungs. The presence of glass fibre may be readily explained on the basis of previous lagging with modern insulation materials.

$X$ ray microanalysis of fibres from BAL fluid preparations may be complicated by several factors. Iron, present in the coating of ferruginous bodies but also important in the identification of amosite, anthophyllite, crocidolite, and actinolite may interfere with the interpretation of the results. Churg and Warnock reported that only 46 of 123 bodies isolated for diffraction in their laboratory could be analysed because of small quantities of iron and calcium in the coat material of the remaining bodies that interfered with the accurate measurement of the chemical composition of the core. ${ }^{9}$ Possibly, also, iron present in blood contaminating the lavage sample may complicate microanalysis patterns. Similarly, since a sodium peak is typical of crocidolite, the addition of sodium during bleaching with sodium hypochlorite may complicate the interpretation of the data. In five of the asbestos exposed subjects studied in the present work microanalysis of fibres that were morphologically consistent with asbestos confirmed the presence of silica but the proportions of the other elements present were not typical of any given fibre subtype. Excessive quantities of tar in some of the present cases necessitated repetitive digestion and preparation before fibres could be identified as asbestos. This in itself may introduce error: Johnson and colleagues have recently shown that repeated digestion, sonication, and resuspension may lead to loss of fibre that is more pronounced after sodium hypochlorite than potassium hydroxide digestion, and which may produce a disturbed estimation of fibre load. ${ }^{14}$

In conclusion, this study has shown that analysis of BAL fluid with the scanning electron microscope may confirm the presence of asbestos fibres when conventional light microscopy has failed to establish the presence of ferruginous bodies. The technique is of value in confirming past exposure and probably gives a crude quantitative estimate of asbestos load. Further work is required to assess the relation between fibre loads in BAL fluid and in lung tissue as determined by electron microscopy.

Dr Andrew Gellert is supported by a grant from the clinical research committee of the National Heart and Chest Hospitals. 
J Y Kitajewska was funded by SPAID (Society for the Prevention of Asbestosis and Industrial Disease), 38 Drapers Road, Enfield, Middlesex EN2 8LU.

\section{References}

${ }^{1}$ Dodson RF, Greenberg DS, Williams MG Jr, Corn CJ, O'Sullivan MF, Hurst GA. Asbestos content in lungs of occupationally and nonoccupationally exposed individuals. JAMA 1984;252:68-71.

${ }^{2}$ Parkes WR. Silicates and lung disease. Occupational lung disorders. 2nd ed. London: Butterworth, 1982:233-332.

${ }^{3}$ Ashcroft T, Heppleston AG. The optical and electron microscopic determination of pulmonary asbestos fibre concentration and its relation to the human pathological reaction. J Clin Pathol 1973;26:224-34.

${ }^{4}$ Gellert AR, Winter RJD, Uthayakumar S, Langford JA, Rudd RM. Bronchoalveolar lavage and clearance of ${ }^{99} \mathrm{mTc}$-DTPA in asbestosis. Thorax 1984;39:709. (Abstract.)

${ }^{5}$ Gellert AR, Langford JA, Winter RJD, Uthayakumar S, Sinha G, Rudd RM. Asbestosis: assessment by bronchoalveolar lavage and measurement of pulmonary epithelial permeability. Thorax 1985;40:508-14.

${ }^{6}$ Gellert AR, Langford JA, Uthayakumar S, Rudd RM. Bronchoalveolar lavage and clearance of ${ }^{99} \mathrm{mTc}$ labelled DTPA in asbestos workers without evidence of asbestosis. Thorax 1985;40:221. (Abstract.)

${ }^{7}$ Gellert AR, Langford JA, Uthayakumar S, Rudd RM. Bronchoalveolar lavage and clearance of ${ }^{99} \mathrm{~m}$-Tc-DTPA in asbestos workers without evidence of asbestosis. $\mathrm{Br} J$ Dis Chest 1985;79:251-7.

${ }^{8}$ Churg A, Warnock ML. Asbestos fibres in the general population. Am Rev Respir Dis 1980;122:669-78.

${ }^{9}$ Churg A, Warnock ML. Analysis of the cores of asbestos bodies
Gellert, Kitajewska, Uthayakumar, Kirkham, and Rudd $\overline{ }$

from members of the general population: patients with probable $\bar{Z}$ low-degree exposure to asbestos. Am Rev Respir Dis 1979;120:781-6.

${ }^{10}$ Warnock ML, Prescott BT, Kuwahara TJ. Numbers and types of $\overrightarrow{\bar{F}}$ asbestos fibres in subjects with pleural plaques. Am J Pathol $\stackrel{?}{+}$ 1982;109:37-46.

${ }^{11}$ Rowlands N, Gibbs GW, McDonald AD. Asbestos fibres in the lungs of chrysotile miners and millers-a preliminary report. $\overline{\bar{N}}$ Ann Occup Hyg 1982;26:411-5.

${ }^{12}$ Gylseth B, Mowe G, Wannag A. Fibre type and concentration in $\stackrel{\mathbb{D}}{\varrho}$ the lungs of workers in an asbestos cement factory. $\mathrm{Br} J$ Ind Med 1983;40:375-9.

${ }^{13}$ Rogers AJ. Determination of mineral fibre in human lung tissue by $\overrightarrow{0}$ light microscopy and transmission electron microscopy. Ann Occup Hyg 1984;28:1-12.

14 Johnson NF, Lincoln JL, Wills HA. Analysis of fibres recovered from lung tissue. Lung 1984;162:37-47.

${ }^{15}$ Dodson RF, Williams MG Jr, McLarty JW, Hurst GA. Asbestos bodies and particulate matter in sputum from former asbestos workers: an ultrastructural study. Acta Cytol 1983;27:635-40. ఉ

${ }^{16}$ De Vuyst P, Mairesse M, Gaudichet A, Dumortier P, Jedwab J, $\omega$ Yernault JC. Mineralogical analysis of bronchoalveolar lavage $-\overrightarrow{ }$ fluid as an aid to diagnosis of "imported" pleural asbestosis. Thorax 1983;38:628-9.

${ }^{17}$ Bignon J, Sebastien P, Gaudichet A, Bientz M. Analysis of mineral particles recovered by bronchoalveolar lavage for the diagnosis of dust related lung diseases. Am Rev Respir Dis 1978;117:218. (Abstracts.)

${ }^{18}$ Wehrung JM, McAlear JH. Surveying for asbestos and the SEM. $\stackrel{\rho}{\supset}$ In: Symposium on electron microscopy of microfibres. Proceedings of the first FDA office of science. Summer symposium. Pennsylvania State University. 23-25 August 1976. Washington: US Department of Health, Education and Welfare, 1976:151-7. (HEW publication (FDA) 77-1033.)

${ }^{19}$ Pooley AD. Electron microscope characteristics of inhaled chrysotile asbestos fibre. $\mathrm{Br} J$ Ind Med 1972;29:146-53.

\section{Correspondence and editorials}

The British Journal of Industrial Medicine welcomes correspondence relating to any of the material appearing in the journal. Results from preliminary or small scale studies may also be published in the correspondence column if this seems appropriate. Letters should be not more than 500 words in length and contain a minimum of references. Tables and figures should be kept to an absolute minimum. Letters are accepted on the understanding that they may be subject to editorial revision and shortening.

The journal now also publishes editorials which are normally specially commissioned. The Editor welcomes suggestions regarding suitable topics; those wishing to submit an editorial, however, should do so.only after discussion with the Editor. 